Article

\title{
Design of Silk-Elastin-Like Protein Nanoparticle Systems with Mucoadhesive Properties
}

\author{
Rachael N. Parker, Wenyao A. Wu, Tina B. McKay, Qiaobing Xu and David L. Kaplan * \\ Department of Biomedical Engineering, Tufts University, Medford, OR 02155, USA; \\ rachael.parker@tufts.edu (R.N.P.); annie.wu@tufts.edu (W.A.W.); tmckay333@gmail.com (T.B.M.); \\ qiaobing.xu@tufts.edu (Q.X.) \\ * Correspondence: david.kaplan@tufts.edu; Tel.: +617-627-3251
}

Received: 5 October 2019; Accepted: 6 November 2019; Published: 12 November 2019 updates

\begin{abstract}
Transmucosal drug delivery is a promising avenue to improve therapeutic efficacy through localized therapeutic administration. Drug delivery systems that increase retention in the mucosal layer are needed to improve efficiency of such transmucosal platforms. However, the applicability of such systems is often limited by the range of chemistries and properties that can be achieved. Here we present the design and implementation of silk-elastin-like proteins (SELPs) with mucoadhesive properties. SELP-based micellar-like nanoparticles provide a system to tailor chemical and physical properties through genetic engineering of the SELP sequence, which enables the fabrication of nanoparticles with specific chemical and physical features. Analysis of the adhesion of four different SELP-based nanoparticle systems in an artificial mucus system, as well as in in vitro cellular assays indicates that addition of mucoadhesive chemical features on the SELP systems increases retention of the particles in mucosal environments. The results indicated that SELP-based nanoparticles provide a useful approach to study and develop transmucosal protein drug delivery system with unique mucoadhesive properties. Future studies will serve to further expand the range of achievable properties, as well as the utilization of SELPs to fabricate mucoadhesive materials for in vivo testing.
\end{abstract}

Keywords: silk-elastin-like protein; mucoadhesion; transmucosal drug delivery; nanoparticles

\section{Introduction}

Mucus membranes that line the surfaces of many organs establish a protective barrier to microbial infection and unwanted foreign objects in the body through trapping and efficient removal. Consisting of up to $95 \%$ water, mucus layers are composed of hydrophilic glycoproteins known as mucins. Mucins comprise 3-5\% of the mucus composition and are key to the barrier properties of mucus, providing structural integrity through physical entanglements and crosslinks [1]. Inorganic salts, lipids, carbohydrates, microbes, and enzymes are also present in the mucus. Although mucus barriers are essential to human health, their dynamic properties present a major challenge to drug delivery. Mucus turnover rates (i.e., time from initial mucus production to the time of complete replacement) range from minutes (e.g., in ocular mucosa [2]) to 1-2 days (e.g., in gastric and intestinal mucosa [3]), which leads to the rapid clearance of transmucosal and orally administered drugs.

Localized routes of administration include ocular, vaginal, nasal, buccal, and rectal mucosa, whereas oral administration relates to gastrointestinal mucosa. Mucoadhesive drug delivery systems that can adhere to the mucus layer and quickly penetrate the gel-like matrix offer a promising solution to the administer therapeutics. This strategy would provide a localized drug-reservoir allowing for prolonged release to the underlying submucosal tissue. This approach is also advantageous as it requires lower systemic doses in order to achieve an optimal therapeutic effect by favoring localized transmucosal delivery of the drugs [4,5]. Increased systemic bioavailability from prolonged 
drug residence times and improved epithelium absorption also represent promising advantages for transmucosal drug delivery. Localized and systemic delivery of therapeutics benefit from extended mucosal interactions, which leads to higher drug efficacy. However, major challenges to mucus retention and penetration stem from several physiological properties including the $\mathrm{pH}$ of the mucosal environment, activity of enzymes in the mucus, fluid volume, thickness of the mucus layer, and mucus turnover rates [6]. The efficiency of mucoadhesion depends on the interactions of the drug delivery system with the mucus.

Despite the diverse and dynamic microenvironment, the mucosal surface provides numerous physical and chemical features that can be exploited to increase mucoadhesion of carrier particles in drug delivery systems [6-8]. These approaches include particles with tailored hydrogen-bonding, electrostatic interactions, hydrophilicity, thiolation, and specific binding to mucins, as well as precise control over size and shape of the substrate [9-15]. Numerous mucoadhesive designs have been developed to improve retention of particles in mucus membranes, such as lipids [16], lectins [17], chitosan [18], synthetic polymers [19], and other biopolymers [9,20] in the form of adhesive tablets [21], micro- and nanoparticles [22], films [23], nanogels [24], and sprays [25]. For example, chitosan represents a widely utilized construction for developing mucoadhesive drug delivery systems. Mucoadhesive $\mathrm{N}$-trimethyl chitosan chloride-coated poly (lactic-co-glycolic acid) nanoparticles improved retention in the intestinal mucus layer and increased bioavailability of insulin in diabetic rats [18]. However, these systems are often limited in tunability and generally require multi-step processes to impart desired chemistries or properties to the system. Additionally, approaches such as these often result in materials with limited utility because of the tedious nature of their synthesis. Our approach presents a novel route to develop mucoadhesion systems with a range of functionalities through modifications of the biopolymer sequence using genetic engineering, which increases the scope of materials that can be produced. Multifunctional platforms can enable highly specific and complex systems to greatly increase efficacy of transmucosal drug delivery. Further development of drug delivery systems that can be tailored to the mucosal environment and respond to local chemical differences is critical to the design of mucoadhesive particles with high drug efficacy.

Silk-elastin-like proteins (SELPs) have been extensively implemented in a variety of applications including biomaterials fabrication [26-29] and drug delivery systems [30-33]. Characterized by a repeating silk and elastin block copolymer structure, SELPs form a unique class of protein-based materials that are biocompatible, biodegradable, and highly tunable in terms of chemistry, size, and properties [26,31,32,34]. Through genetic engineering, modifications of the SELP amino acid composition and overall polymer size can be achieved, providing a route to tightly control the chemical and physical properties. Further utilization of these materials for the delivery of hydrophobic drugs to HeLa cells [31] and for self-assembled biomaterials demonstrate the range of properties achievable using SELPs [34]. The hydrophobic silk domain (GAGAGS) provides structural support and the hydrophilic elastin domain (GXGVP) enables modification of the chemical and stimuli-responsive properties through mutation of the variable sequence position " $\mathrm{X}$ ". We have previously reported the development of a library of SELP proteins by modification of the elastin sequence to generate SELPs with stimuli-responsive properties to $\mathrm{pH}$, redox, temperature, electric field, and ionic strength, and utilized functional materials screening to isolate useful sequences from the library for further materials characterization [35]. The block copolymer structure of SELPs provides an additional design feature that enables future combinations of sequences with varying functionalities that will not affect the structure or inhibit material fabrication as reported in our previous work [36,37]. Thus, these proteins are useful candidates for designing mucoadhesive biopolymer systems because of their customizable physiochemical properties, where biocompatible SELP-based drug delivery systems that exploit favorable properties of mucosal membranes can be utilized.

The goal of the present study is to genetically engineer SELP-based materials and assess the effectiveness of SELP-based nanoparticles as mucoadhesive materials. We hypothesized that modifying the elastin domain to include specific charged amino acids and thiol-containing amino acid side chains 
(i.e., $\mathrm{R}, \mathrm{K}, \mathrm{E}, \mathrm{C}$ for-arginine, lysine, glutamic acid, and cysteine) would provide improved mucoadhesion and drug retention in the mucosal epithelium. We designed four SELP systems that were then used to fabricate micellar-like nanoparticles incorporating the molecular probe, 8-anilinonaphthalene-1-sulfonic acid (ANS) as a model drug. This fluorescent compound allowed tracking of the nanoparticles in bio-mimetic mucus and in epithelial intestinal cell culture systems. The results support bioengineered SELP-drug-based delivery system designs as a useful strategy to explore toward future transmucosal drug delivery.

\section{Results and Discussion}

We have previously reported the design and production of recombinant SELP proteins with silk and elastin ratios of 1:4 (i.e., S2E8X), which contained arginine, lysine, glutamic acid, and cysteine in the variable position " $X$ " of the elastin domain [35]. In the current study, we employed SELPs termed S2E8R, S2E8K, S2E8E, and S2E8C for the fabrication of micellar-like nanoparticles as model systems for investigating the utility of SELP proteins as mucoadhesive materials for drug delivery. The use of recombinant protein expression and purification methods allows for highly homogenous starting materials, where proteins are produced with yields from $20-40 \mathrm{mg} / \mathrm{L}$ following purification.

\subsection{Characterization of ANS-Loaded SELP Nanoparticles}

ANS is a hydrophobic, solvatochromic dye used to study conformational changes in protein structure [38], as well as to investigate drug loading in synthetic polymer systems [39]. Upon decreasing solvent polarity, a blue shift is exhibited in the ANS fluorescence spectrum, and the wavelength of maximum fluorescence intensity $(\lambda \max )$ changes from $545 \mathrm{~nm}$ to $470 \mathrm{~nm}$. This shift results from a high affinity interaction of the dye with hydrophobic regions of the protein. Given the hydrophilic-hydrophobic block copolymer structure of the SELPs, ANS can be used as a hydrophobic trigger for micelle formation [31]. Specifically, the addition of ANS to SELPs in a polar solution facilitates assembly of micellar-like nanoparticles through interaction with the hydrophobic silk domain and creates a reporter system for analysis and tracking of the SELP nanoparticle system in subsequent studies presented here (Figure 1A).

Fluorescence spectroscopy measurements were used to assess the efficiency of SELP nanoparticle assembly upon addition of ANS. Following the previously described procedures using water as a solvent [31], ANS was added to each SELP solution and solutions were allowed to equilibrate prior to fluorescence measurements. Emission spectra corresponding to the aqueous SELP solutions before and after adding ANS, as well as an ANS only control, are displayed in Figure 1B. The emission spectrum of ANS only shows characteristic fluorescence $(\lambda \max =545 \mathrm{~nm})$ consistent with the hydrophobic dye in a polar environment. Additionally, each SELP protein excited at the same wavelength displayed minimal fluorescence (Figure 1B and Figure S1). Upon addition of ANS to the aqueous SELP solutions, all spectra exhibited a large shift in $\lambda \max$, as well as a change in overall fluorescence intensity. Collectively, the SELP+ANS spectra are indicative of ANS in a nonpolar environment, which suggests encapsulation in the core of the SELP micelles. The $\lambda$ max values (Table 1) show that S2E8K exhibits the largest shift in $\lambda \max$ with $\mathrm{a} \lambda \max =470 \pm 2 \mathrm{~nm}$ compared to S2E $8 \mathrm{R}=479 \pm 3 \mathrm{~nm}, \mathrm{~S} 2 \mathrm{E} 8 \mathrm{E}=477 \pm 2 \mathrm{~nm}$, and S2E8C $=500$ $\pm 4 \mathrm{~nm}$. S2E8K and S2E8E display an increase in fluorescence signal approximately six-fold higher than that of S2E8C. However, S2E8R shows the greatest increase in fluorescence intensity corresponding to approximately ten-fold higher emission than that of S2E8C and approximately 1.6-fold higher than both S2E8K and S2E8E determined by comparing the fluorescence intensity value at $\lambda$ max for each sample. These results suggest ANS encapsulation occurs with all protein sequences analyzed, and that S2E8R sequesters the highest concentration of ANS. This enrichment may be attributed to an increased affinity of the negatively charged dye and the arginine side chains found in the S2E8R construct indicating that favorable electrostatic interactions may increase uptake of ANS or enable stabilization of the dye in the micelle core. Interestingly, S2E8K and S2E8E show similar wavelength shifts, as well as similar intensity of emission despite the different charges associated with these proteins. However, 
the hydrophobic domains are the same, suggesting that the hydrophobic effect associated with the micelle formation is the strongest force contributing to the protein-dye association. This is further exemplified by the increase in fluorescence intensity shown by S2E8R. While S2E8R also contains the same hydrophobic domain, it appears to sequester more dye than S2E8K and S2E8E, indicating favorable electrostatic contributions to the dye sequestration. Although S2E8K also contains positively charged amino acid groups, the guanine side chain on the arginine groups of S2E8R likely forms a more stable complex with ANS than the amine group on the lysine from S2E8K given the more basic nature (i.e., pKa 12.5 compared to $\mathrm{pKa} 10.5$ ) of the guanine group compared to the amine group resulting in a more stable cation and thus more stable ionic interaction. Additionally, S2E8C shows the lowest uptake of ANS. This finding may also be attributed to disulfide bond formation, which can reduce the ability of the SELP to sequester ANS. However, all SELPs evaluated demonstrate ANS uptake, which enables tracking of the system via fluorescence in future studies presented here.

A
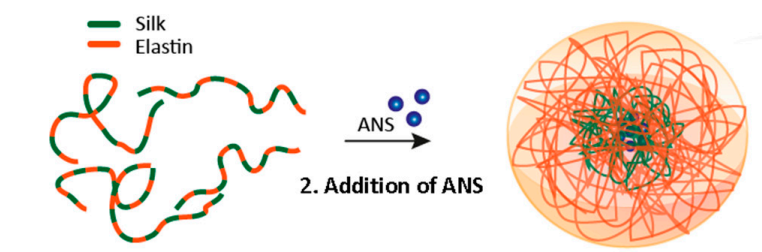

1. SELP Protein Chains in Solution

3. Formation of SELP-ANS loaded Np

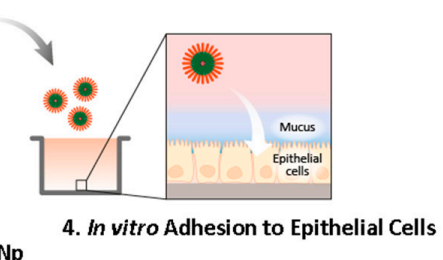

B

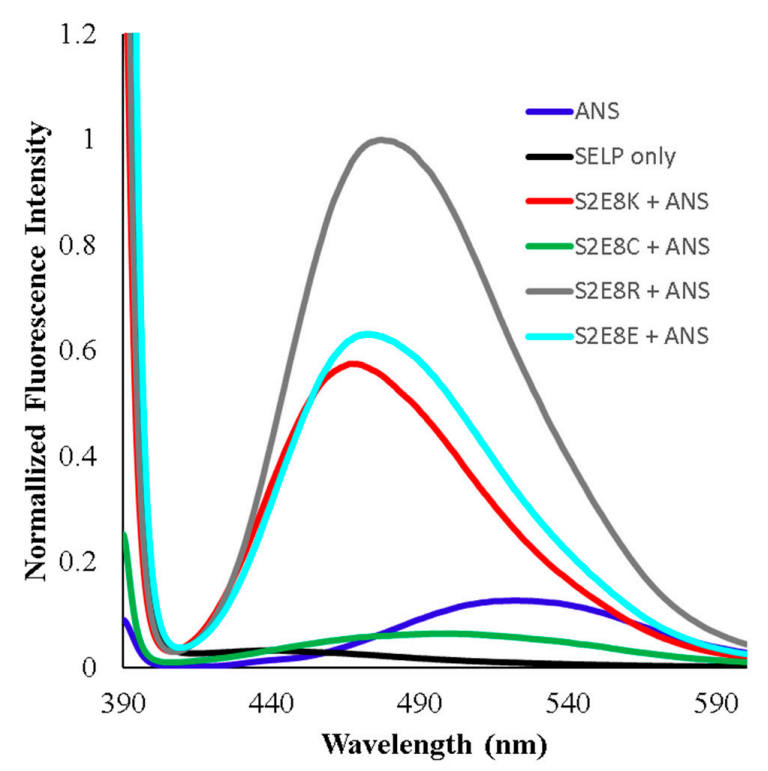

Figure 1. 8-Anilinonaphthalene-1-sulfonic acid (ANS)-loaded silk-elastin-like proteins (SELP) assembly mechanisms and fluorescence characterization. (A) Assembly scheme shows ANS uptake in SELP micellar-like nanoparticles shown in four steps. 1. Depiction of free protein chains in solution. 2. Addition of ANS to induce micelle formation. 3. Depiction of the SELP-ANS loaded micelle-like structures. 4. Adhesion tests using in vitro cellular analysis. (B) Fluorescence characterization of SELPs before addition of ANS (black), after addition of ANS (S2E8K-red, S2E8C-green, S2E8R-grey, S2E8E-cyan), and free ANS in solution (blue). The black curve is representative of the protein samples without the addition of ANS. Spectra for each SELP sample is provided in Supplemental Information.

To further probe encapsulation of ANS during SELP nanoparticle fabrication, DLS was implemented to measure the changes in hydrodynamic radii. Measurements of SELPs ranging in concentration from $0.1-1 \mathrm{mg} / \mathrm{mL}$ resulted in no observable differences in particle size as concentration was increased, indicating that aggregates do not form as concentration increases. The average 
hydrodynamic radii of the ANS-loaded SELP nanoparticles at $0.1 \mathrm{mg} / \mathrm{mL}$ (i.e., the concentration used for all presented studies) is $78 \pm 1 \mathrm{~nm}$ for S2E8R, $102 \pm 3 \mathrm{~nm}$ for S2E8K, $206 \pm 3 \mathrm{~nm}$ for S2E8E, and $73 \pm 4 \mathrm{~nm}$ for S2E8C (Table 1). Interestingly, S2E8E had an average particle size two-fold greater than all other SELP sequences. This size difference may be attributed to the negatively charged carboxyl groups of the glutamic acid side chains in the S2E8E sequence. Additionally, free protein chains in solution average around $4.5 \mathrm{~nm}$ [40] suggesting that for each sample, efficient micelle formation occurred. The polydispersity index (PDI) of less than 0.5 for all constructs, signifies relative homogeneity of nanoparticle sizes.

The proposed mechanism of assembly (Figure 1A) suggests that the hydrophobic effect is the driving force in formation of the SELP micelles and is consistent with previously investigated assembly of SELPs [34,40]. Collectively, fluorescence and DLS data indicate the formation of micellar-like nanoparticles and their efficient encapsulation of ANS for the four SELPs studied here, supporting further analysis of their mucoadhesive properties in the context of particle morphology delivery systems.

Table 1. SELP sequences and nanoparticle characterization. Molecular weight (MW), nanoparticle $(\mathrm{Np})$ size, nanoparticle polydispersity (PDI), and maximum recorded wavelength $(\lambda \max )$ with highest fluorescence intensity are provided for each SELP sequence.

\begin{tabular}{cccccc}
\hline Name & Sequence & $\begin{array}{c}\text { MW } \\
\mathbf{( k D a )}\end{array}$ & $\begin{array}{c}\text { Np Size } \\
\mathbf{( n m )}\end{array}$ & Np PDI & $\begin{array}{c}\text { Fluorescence } \\
\lambda \mathbf{m a x}(\mathbf{n m})\end{array}$ \\
\hline S2E8R & $\begin{array}{c}\text { GAGAGSGAGAGSGVGVPGVGVPGVGVP } \\
\text { GVGVPGRGVPGVGVPGVGVPGVGVP }\end{array}$ & 63 & $78 \pm 1$ & 0.2 & $479 \pm 3$ \\
\hline S2E8K & $\begin{array}{c}\text { GAGAGSGAGAGSGVGVPGVGVPGVGVP } \\
\text { GVGVPGKGVPGVGVPGVGVPGVGVP }\end{array}$ & 57 & $102 \pm 3$ & 0.3 & $470 \pm 2$ \\
\hline S2E8E & $\begin{array}{c}\text { GAGAGSGAGAGSGVGVPGVGVPGVGVP } \\
\text { GVGVPGEGVPGVGVPGVGVPGVGVP }\end{array}$ & 65 & $206 \pm 3$ & 0.2 & $477 \pm 2$ \\
\hline S2E8C & $\begin{array}{c}\text { GAGAGSGAGAGSGVGVPGVGVPGVGVP } \\
\text { GVGVPGCGVPGVGVPGVGVPGVGVP }\end{array}$ & 58 & $73 \pm 4$ & 0.4 & $500 \pm 4$ \\
\hline
\end{tabular}

\subsection{Evaluation of SELP Nanoparticle Mucoadhesive Properties}

Because of the variability of mucus production by mucus-secreting cells in laboratory cultures, "bio-similar mucus" (BM) has been utilized as a controlled means to study the interaction of drug delivery systems with the mucus layer [7,41,42]. We implemented a 2D, cell-free BM model to investigate the interactions of the SELP nanoparticles in a mucus-rich environment. As previously described, SELPs containing arginine (R), lysine (K), glutamic acid (E), and cysteine (C) substitutes were selected for investigation as possible designs for mucoadhesive delivery systems, as these proteins contain charged groups and thiol groups resulting from the selected modification of the elastin " $X$ " amino acid. Many studies have demonstrated the importance of electrostatic interactions in mucoadhesion $[9,19,43,44]$. Additionally, mucoadhesive nanoparticle drug delivery systems containing thiol groups have resulted in increased retention because of the propensity for disulfide bond formation with mucins containing thiol groups $[44,45]$. Therefore, we hypothesized that S2E8K, S2E8R, S2E8E, and S2E8C may have favorable chemistries to facilitate retention of the nanoparticles in the mucosal membrane.

To test this hypothesis, BM was aliquoted into a standard 48-well cell culture plate followed by seeding of nanoparticles onto the mucus layer and subsequent incubation for $24 \mathrm{~h}$, a time-frame consistent with gastrointestinal mucus turnover rates [3]. To reduce the retention of loosely bound particles, samples were washed with PBS and centrifuged to retain the mucus layer prior to imaging with fluorescence microscopy. Untreated samples and unbound ANS (i.e., free ANS in solution) were included, with the later providing an assessment of the diffusion rate of free dye molecules in the mucus layer (Figure 2A,F). Fluorescence microscopy images of the SELP nanoparticles indicated retention of nanoparticles in all samples, detected by imaging fluorescence emitted by encapsulated ANS molecules 
(Figure 2B-E). Free ANS was not detected in the nanoparticle untreated samples. DLS measurements indicate nanoparticles from 73 to $206 \mathrm{~nm}$. However, it can be seen from the fluorescence images that large aggregates of several $\mu \mathrm{m}$ are formed throughout the mucus layer indicating accumulation of the particles. Particle analysis from ANS fluorescence (ImageJ) was used for quantitative assessment of nanoparticles retention in the mucus layer, demonstrating that S2E8C and S2E8K nanoparticles had the greatest retention (Figure 3). S2E8C nanoparticles showed the strongest affinity for the BM with a two-fold higher retention than S2E8K nanoparticles, and a three-fold and five-fold greater retention than S2E8R and S2E8E, respectively with S2E8E resulting in the lowest affinity of all samples in the BM model as determined by relative particle abundance (Figure 3).

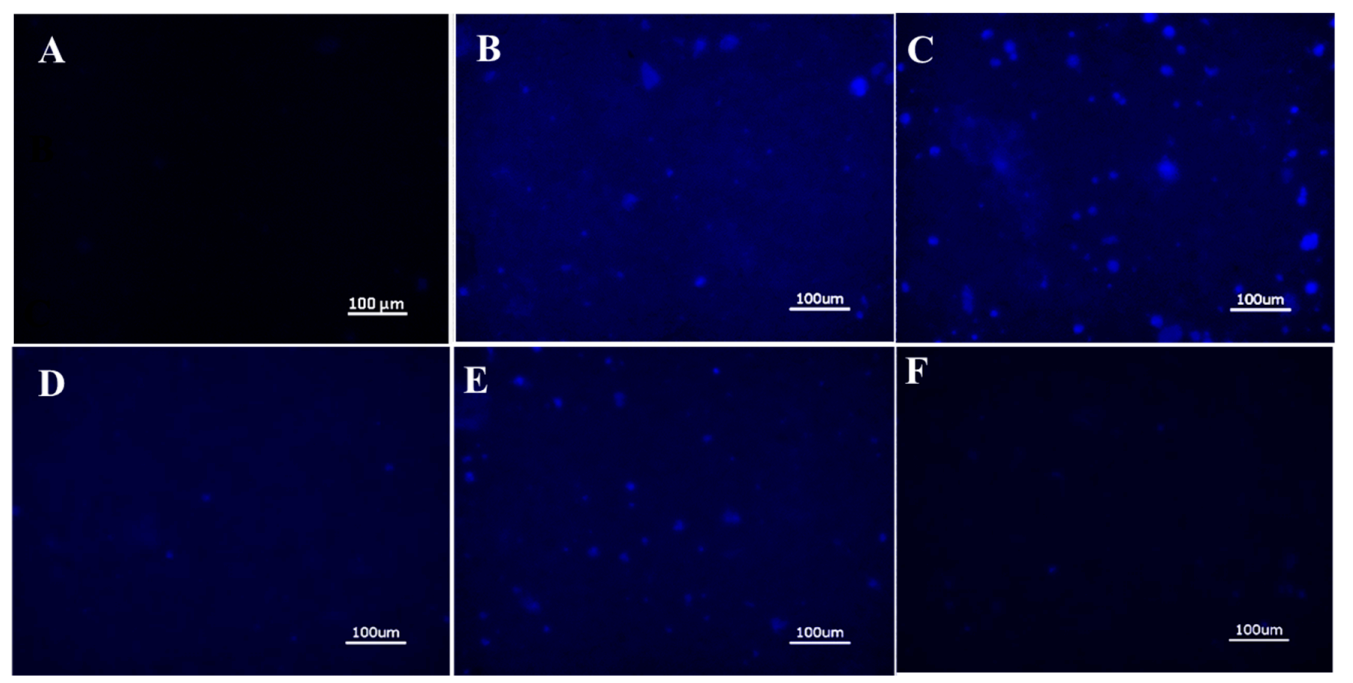

Figure 2. Fluorescence microscopy of bio-similar mucus SELP nanoparticle adhesion. Representative images of (A) untreated control, (B) S2E8R ANS-loaded nanoparticles, (C) S2E8K ANS-loaded nanoparticles, (D) S2E8E ANS-loaded nanoparticles, (E) S2E8C ANS-loaded nanoparticles, (F) Free ANS. All scale bars are $100 \mu \mathrm{m}$.

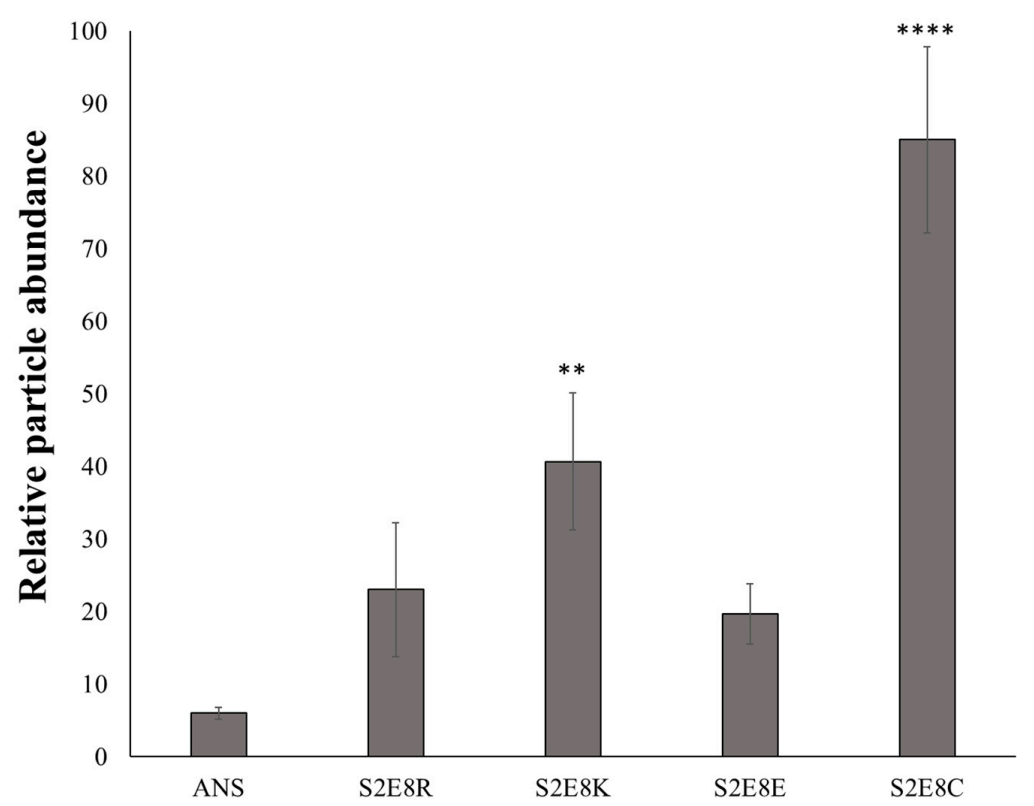

Figure 3. Quantification of SELP nanoparticle fluorescence microscopy images. Quantification of SELP nanoparticle retention in biosimilar mucus model. Counts generated by particle analysis using ImageJ software. Error bars represent standard deviation with $\mathrm{n}=3$. Statistical significance based on a one-way with Tukey's multiple comparison shown. ${ }^{* *} p<0.01,{ }^{* * * *} p<0.0001$. 
As indicated by the lack of observed fluorescence in the free ANS samples and the localized areas of fluorescence observed in ANS-loaded nanoparticles, SELP nanoparticle encapsulation of the model fluorophore ANS was required for improving the retention of the compound in the mucus layer. Enhanced affinity of S2E8R and S2E8K to the BM over S2E8E likely resulted from favorable electrostatic interactions of the nanoparticles with the negatively charged mucin. These results were consistent with previous studies that have highlighted the importance of charge in maintaining drug system interactions with the mucosal membrane where positively charged nanoparticles lead to increased drug uptake [46-49]. The strongest affinity for the BM resulted from S2E8C, which contains cysteine as the variable amino acid. The presence of thiol groups in this nanoparticle system provided the ability to form disulfide bonds, likely leading to longer residence of the S2E8C ANS-loaded nanoparticles in the BM model.

\subsection{In Vitro Cytotoxicity of ANS-Loaded Nanoparticles}

To determine the biocompatibility of the SELP constructs, we evaluated the cell viability of Caco-2 and HT29-MTX cultures after incubation with the ANS-loaded SELP nanoparticles. No significant impact on cell viability was observed after $24 \mathrm{~h}$ when cells were dosed with nanoparticles up to $0.1 \mathrm{mg} / \mathrm{mL}$, which was the highest concentration implemented in the in vitro assays (Figure $4 \mathrm{~A}, \mathrm{~B}$ ). SELPs have been previously shown to be biocompatible [31]. Therefore, our findings are consistent in showing that the SELP constructs developed in this study were non-toxic in vitro, thus supporting the applicability of a broad range of SELP-based systems for drug delivery.

A

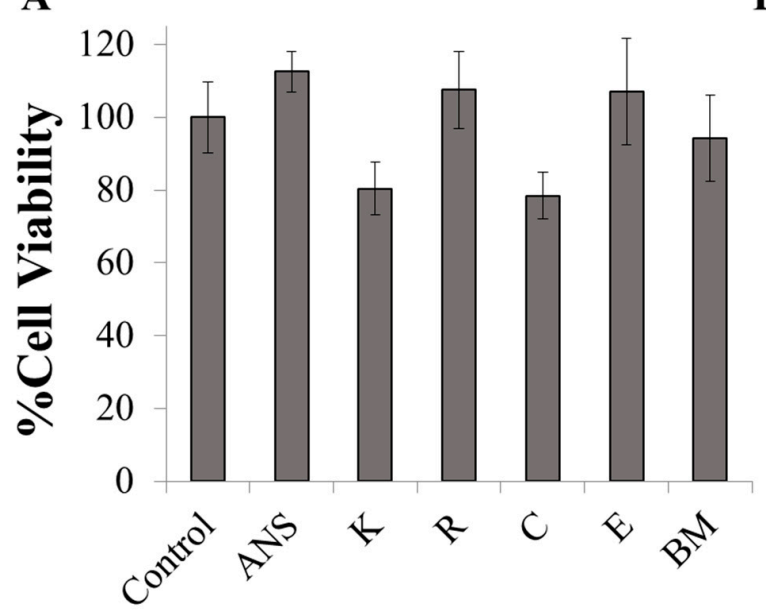

B 140

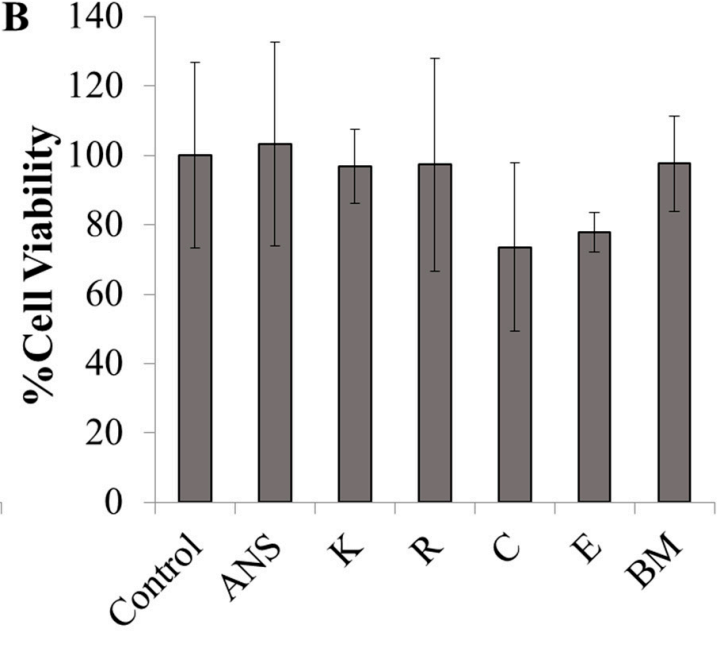

Figure 4. MTT assay results for (A) Caco-2 and (B) HT29-MTX following $24 \mathrm{~h}$ SELP nanoparticle incubation at $1 \mathrm{mg} / \mathrm{mL}$. Error bars represent standard deviation with $\mathrm{n}=3$. No significant difference observed between control cells and treatment groups for Caco-2 or HT29-MTX based on a one-way ANOVA with Tukey's multiple comparison.

\subsection{Cellular Adhesion of ANS-Loaded SELP Nanoparticles}

Further characterization of the adhesive properties of the SELPs was completed through examination of nanoparticle interactions with two different mucosal cell lines, Caco-2 and HT29-MTX. Retention of the nanoparticles in the mucus secreting epithelial HT29-MTX cells was compared to the Caco-2 cell line, which does not produce mucus. To evaluate the role of mucus production on adhesion of the ANS-loaded SELP nanoparticles in the cell layer, each SELP nanoparticle system was seeded on confluent Caco-2 and HT29-MTX cells and incubated for $24 \mathrm{~h}$, after which the media were removed, and the cell layers washed with PBS and fixed with PFA. Untreated control cells were stained for the presence of F-actin using Alexa FluorTM 647 phalloidin and with nuclear DAPI stain to confirm integrity of the cell layer (Figure S2). 
Fluorescence microscopy of the Caco-2 cells showed no retention of free ANS and no retention of S2E8C in comparison to the untreated cell layer (Figure 5A,E,F). Caco-2 cells do not produce mucus and it is therefore not unexpected that S2E8C would show diminished interactions compared to the $\mathrm{BM}$ analysis as the thiol containing cysteine groups are likely responsible for this result. S2E8R, S2E8K, and S2E8E displayed fluorescence signals observed from encapsulated ANS, suggesting retention of nanoparticles in the cell layer (Figure 5B-D). S2E8K and S2E8R nanoparticles were localized to the cell body and were characterized by discrete and uniform groupings suggesting possible endocytosis of the particles. However, this requires future validation to confirm. S2E8E appeared in larger amorphous clusters that indicated possible aggregation at the cell surface. SELP adhesion to hCSSCs was also assessed as an additional non-mucosal control cell line (Figure S3). Similar to the Caco-2 analysis, only S2E8K displayed retention in the cell layer, and no further adhesion was observed in the remaining systems.

To determine if the presence or absence of a mucus layer promoted increased drug retention in vitro, we assessed ANS-loaded SELP adhesion in a culture of HT29-MTX. In comparison, assessment of the HT29-MTX cells revealed adhesion of S2E8R, S2E8K, and S2E8E SELP samples to the cell layer, and as with the Caco-2 cells, no retention of the unbound dye (Figure 6). Additionally, S2E8C presented possible mucolytic properties based on the lack of mucus and nanoparticles signal observed in these samples. However, further studies are required to investigate this phenomenon. Determination of relative fluorescence abundance indicated a 10-fold increase in retention for S2E8E, 5-fold for S2E8R, and 32-fold for S2E8K, as determined by particle analysis from fluorescence imaging (ImageJ) (Figure 7A-C). To probe the role of mucus adhesion, we evaluated localization patterns of the SELPs with Mucin 2 (Muc2), an oligomeric glycoprotein responsible for mucus barrier formation [50]. HT29-MTX cells were stained with anti-Muc2 antibody to verify mucus production and accumulation, as well as to further assess the interactions of the nanoparticles with the cell layer. We observed high expression of Muc2 throughout the HT29-MTX culture consistent with the formation of a mucus layer. Regions of nanoparticle and Muc2 co-localization were evident suggesting that the SELPs may bind to the Muc2 glycoprotein, a favorable interaction that would likely improve drug retention in the presence of mucus (Figure 6B-D). Similar localization patterns between ANS-loaded nanoparticles and Muc2 were identified with little variability based on sequence suggesting that each variable amino acid may contribute to these binding interactions, but these mechanisms of adhesion require future studies to elucidate. These studies revealed an increased propensity of the nanoparticles for interaction with the HT29-MTX cell line consistent with the biomimetic mucus studies. 


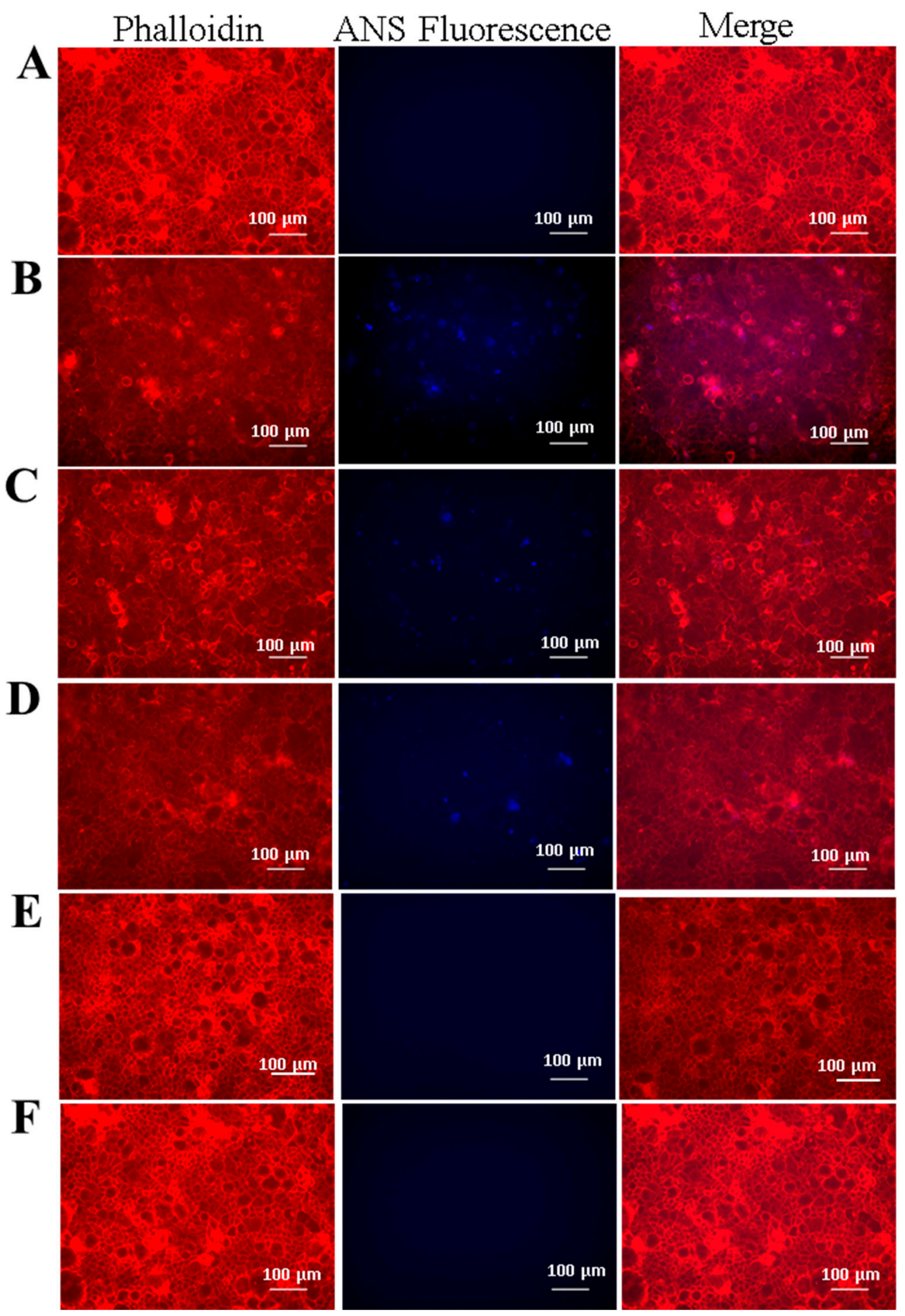

Figure 5. Fluorescence microscopy of Caco-2 cells seeded with ANS-loaded SELP nanoparticles. Representative images of (A) untreated control. (B) S2E8R ANS-loaded nanoparticles. (C) S2E8K ANS-loaded nanoparticles. (D) S2E8E ANS-loaded nanoparticles. (E) S2E8C ANS-loaded nanoparticles. (F) Free ANS. Cells are stained with Alexa FluorTM 647 phalloidin (F-actin, red) $(\lambda \mathrm{ex}=560 \mathrm{~nm}$ and $\lambda \mathrm{em}=645 \mathrm{~nm}$ ). ANS signal (blue) corresponds to $\lambda \mathrm{ex}=360 \mathrm{~nm}$ and $\lambda \mathrm{em}=420 \mathrm{~nm}$. All scale bars are $100 \mu \mathrm{m}$. 


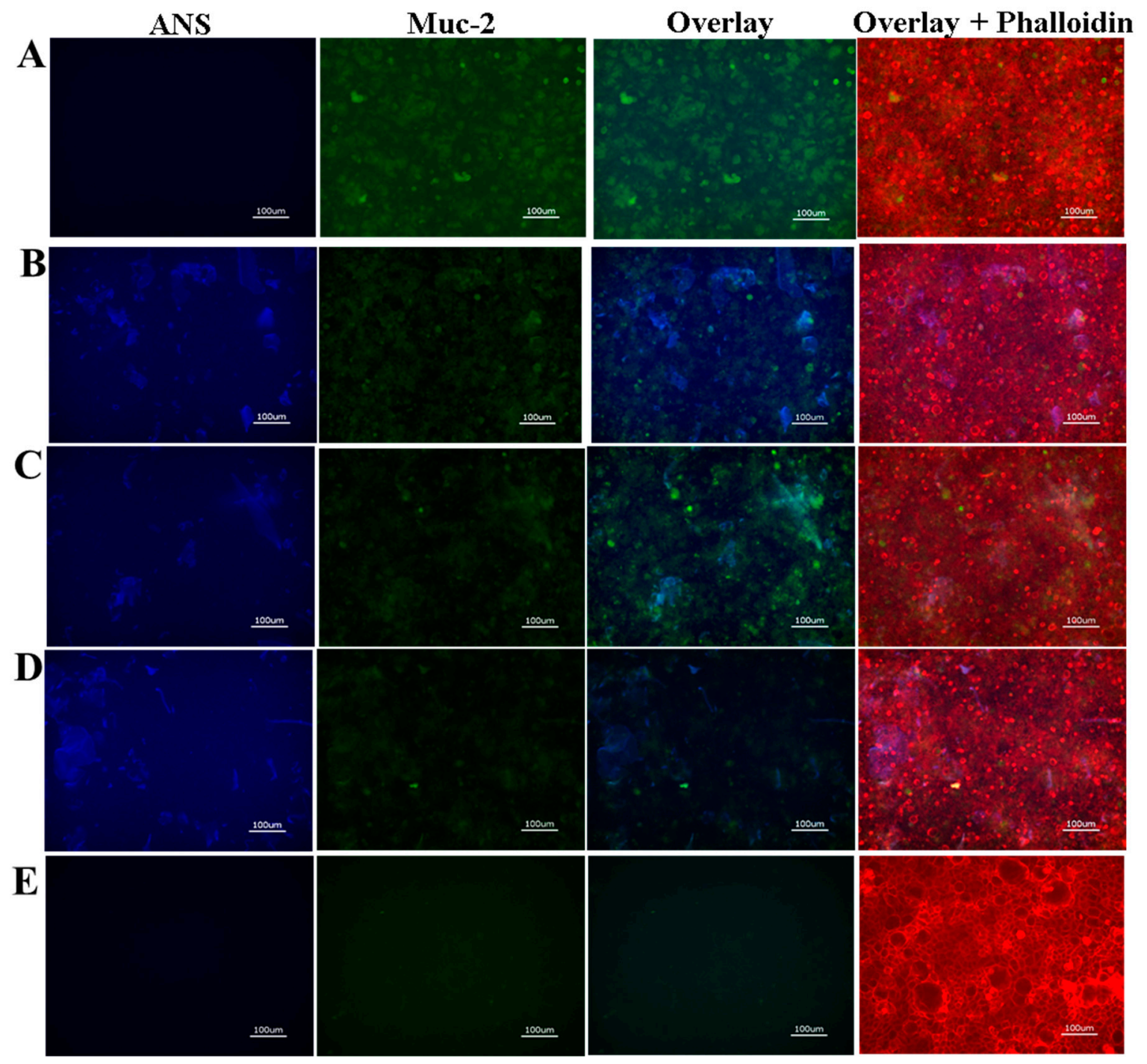

Figure 6. Fluorescence microscopy of HT29-MTX cells with ANS-loaded SELP nanoparticles. Representative images of (A) Free ANS. (B) S2E8R ANS-loaded nanoparticles. (C) S2E8K ANS-loaded nanoparticles. (D) S2E8E ANS-loaded nanoparticles. (E) S2E8C ANS-loaded nanoparticles. Cells are stained with Alexa FluorTM 647 phalloidin (F-actin, red) $(\lambda e x=560 \mathrm{~nm}$ and $\lambda \mathrm{em}=645 \mathrm{~nm})$ and anti-Muc2 (green) $(\lambda \mathrm{ex}=470 \mathrm{~nm}$ and $\lambda \mathrm{em}=525 \mathrm{~nm}$ ). ANS signal (blue) corresponds to $\lambda \mathrm{ex}=360 \mathrm{~nm}$ and $\lambda \mathrm{em}=420 \mathrm{~nm}$. All scale bars are $100 \mu \mathrm{m}$. 

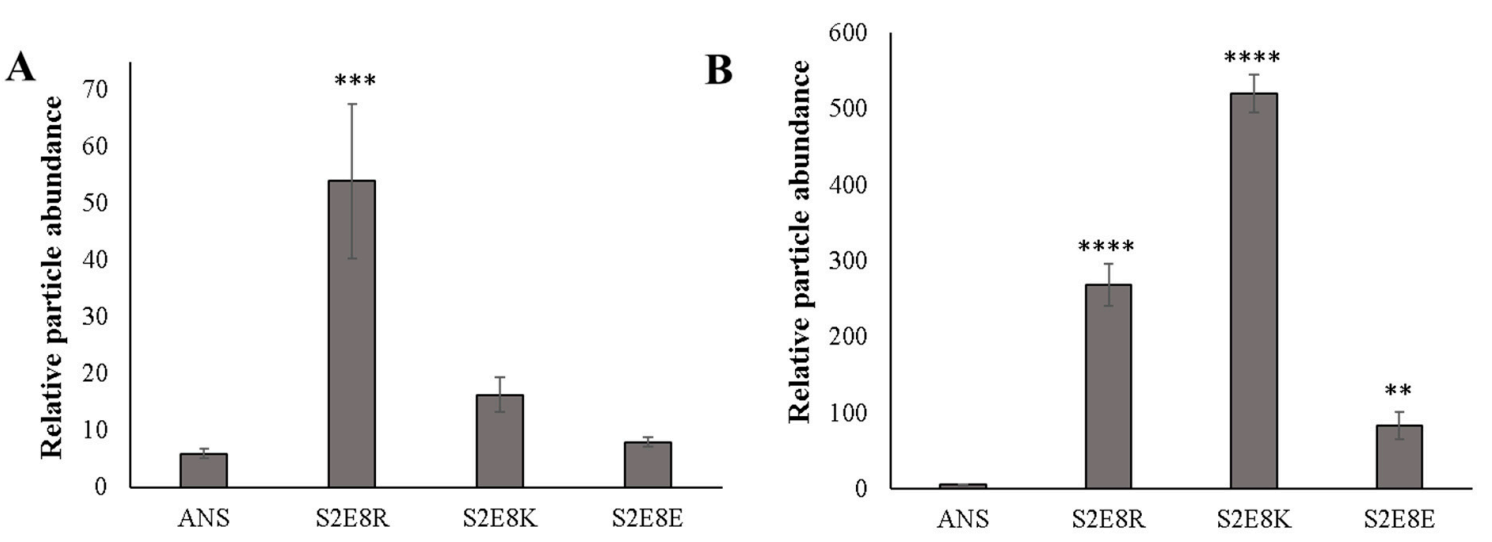

C

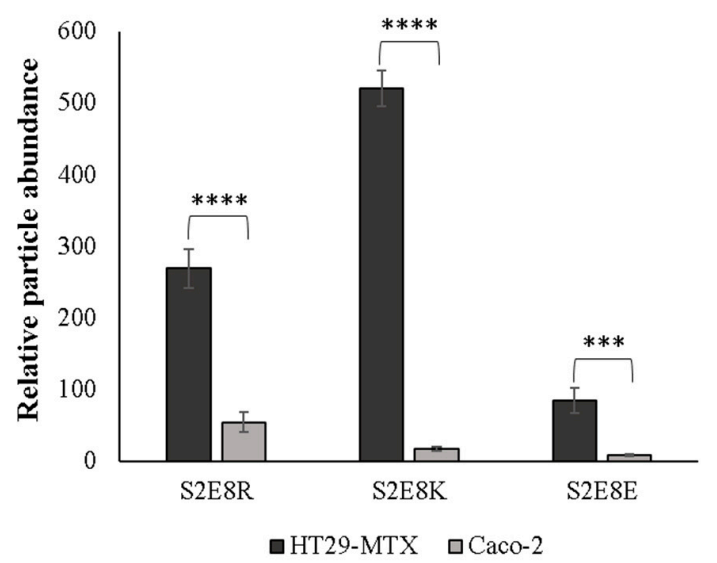

Figure 7. Quantification of SELP nanoparticle fluorescence microscopy images. (A) Quantification of SELP nanoparticle retention in Caco-2 cell model (B) in HT29-MTX cell model and (C) Comparison of SELP nanoparticle retention in HT29-MTX (dark grey) and Caco-2 (light grey) cells. Counts generated by particle analysis using ImageJ software. Error bars represent standard deviation with $n=3$. Statistical significance based on a one-way or two-way ANOVA with Tukey's multiple comparison shown in A-C or $\mathrm{D}$, respectively. ${ }^{* *} p<0.01,{ }^{* * *} p<0.001,{ }^{* * * *} p<0.0001$.

\section{Materials and Methods}

\subsection{Biosynthesis of SELP Proteins}

SELP constructs used in these studies are named according to the nomenclature S2E8X, corresponding to the sequence ((GAGAGS) $)_{2}(\text { GVGVP) })_{4}\left(\right.$ GXGVP) $\left.(\text { GVGVP) })_{3}\right)$ where $\mathbf{X}$ is either $\mathrm{K}, \mathrm{R}$, E, or C. SELPs of 57, 58, 63, and $65 \mathrm{kDa}$ for S2E8K, S2E8C, S2E8R, respectively, were produced according to previously described procedures [31,34]. Briefly, expression vectors containing DNA sequences encoding for S2E8K, S2E8R, S2E8E, and S2E8C were transformed in BL21 (DE3) competent E. coli cells (New England Biolabs, Ipswich, MA, USA) and expressed under the T7 promoter. Following transformation, cells containing the expression plasmids were grown overnight for $16 \mathrm{~h}$ in $50 \mathrm{~mL}$ of Lysogeny Broth (LB) media at $37^{\circ} \mathrm{C}$ with shaking at $250 \mathrm{rpm}$. Athena ES Hyper Broth (Fisher Scientific, Hampton, NH, USA) was then used to dilute the culture in a 1:100 ratio and cells were grown to an optical density (OD) of $0.8-1.0$ before inducing protein expression with the addition of $1 \mathrm{mM}$ isopropyl $\beta$-D-1-thiogalactopyranoside (IPTG). Proteins were expressed at $37^{\circ} \mathrm{C}$ for $5 \mathrm{~h}$ followed by harvesting of cells by centrifugation at $5000 \mathrm{rpm}$ for $15 \mathrm{~min}$. Cells were then resuspended in PBS and stored at $-20{ }^{\circ} \mathrm{C}$ until purification. All SELPs included an $\mathrm{N}$-terminal histidine affinity tag and were purified using standard Ni-NTA affinity chromatography. Following purification, SELPs were dialyzed against deionized water for 3 days using Slide-A-Lyzer ${ }^{\mathrm{TM}}$ G2 Dialysis Cassettes, 10K MWCO (ThermoFisher, 
Waltham, MA, USA) before freeze-drying and storing for further use. Protein purity was assessed using sodium dodecyl sulfate polyacrylamide electrophoresis (SDS-PAGE).

\subsection{Assembly of 8-Anilinonaphthalene-1-Sulfonic Acid (ANS)-Loaded Micellar-Like SELP Nanoparticles}

ANS-loaded micellar-like SELP nanoparticles, herein referred to as SELP nanoparticles, were assembled as previously reported with minor modifications [31]. Briefly, concentrated ANS and SELP stock solutions made in water were mixed to achieve final concentrations of $80 \mu \mathrm{M}$ and $1 \mathrm{mg} / \mathrm{mL}$, respectively. Samples were incubated at $4{ }^{\circ} \mathrm{C}$ on a rotating mixer for $16 \mathrm{~h}$ followed by dialysis against deionized water using Slide-A-Lyzer ${ }^{\mathrm{TM}}$ G2 Dialysis Cassettes, 10K MWCO (ThermoFisher) for 1 day to remove unbound ANS molecules. For all experiments the stock solution was diluted to achieve a final SELP concentration of $0.1 \mathrm{mg} / \mathrm{mL}$.

\subsection{Dynamic Light Scattering (DLS)}

The average particle size and size distribution of the SELP and ANS-loaded SELP micellar-like nanoparticles were measured using a DynaPro Titan dynamic light scattering (DLS) instrument (Wyatt Technology, Santa Barbara, CA, USA). Samples were filtered using a $0.45 \mu \mathrm{m}$ syringe filter prior to analysis and all measurements were completed at $25^{\circ} \mathrm{C}$. SELP and ANS-loaded SELP nanoparticles were analyzed at $0.1-1 \mathrm{mg} / \mathrm{mL}$. Herein we report DLS data as an average of three measurements per sample type.

\subsection{Fluorescence Spectroscopy}

Fluorescence of SELP and ANS-loaded SELP was monitored using a Hitachi F-4500 fluorescence spectrophotometer. Samples were prepared at concentrations of $0.1 \mathrm{mg} / \mathrm{mL}$ and were filtered through a $0.45 \mu \mathrm{m}$ syringe filter before analysis. Excitation of the samples occurred at $388 \mathrm{~nm}$ and spectra were recorded from 390 to $600 \mathrm{~nm}$ using $10 \mathrm{~nm}$ excitation and emission slits. The average fluorescence of three scans is reported for each sample.

ImageJ was used for determining the relative particle abundance for each sample based on the total fluorescence intensity in the DAPI channel $(\lambda e x=360 \mathrm{~nm}$ and $\lambda \mathrm{em}=420 \mathrm{~nm})$. Images were converted into an 8 -bit format followed by automatic threshold adjustment. The total counts per image were averaged over five representative regions of interest for three independent samples to determine the relative particle abundance per sample.

\subsection{Cell Culture-Caco-2 and HT29-MTX Epithelial Cells and hCSSCs, and ANS-Loaded SELP Nanoparticle Adhesion to Epithelial Cell Monolayers}

The HT29-MTX cell line was obtained from the Public Health England Culture Collections (Salisbury, Great Britain). The Caco-2 (CRL-2102) cell line was obtained commercially from ATCC (Rockville, MD, USA). Caco-2 and HT29-MTX cells were grown in Dulbecco's Modified Eagle's Medium (DMEM) (ThermoFisher) containing 10\% v/v fetal bovine serum (FBS) (ThermoFisher) and $1 \%$ antibiotic-antimycotic (ThermoFisher). Cells were maintained at $37{ }^{\circ} \mathrm{C}$ with $5 \% \mathrm{CO}_{2}$. Caco-2 and HT29-MTX cells were used from passage number 15-30 for all experiments. Human corneal stromal stem cells (hCSSCs) were provided by Jim Funderburgh (University of Pittsburg) following isolation from cadaveric corneal limbal tissue using established protocols [51]. hCSSCs (passages 4-5) were cultured in proliferation media composed of low glucose DMEM (Gibco, Grand Island, NY, USA), MCDB-201 (Sigma), 2\% v/v FBS (Gibco), $10 \mathrm{ng} / \mathrm{mL}$ platelet-derived growth factor (PDGF), $10 \mathrm{ng} / \mathrm{mL}$ epidermal growth factor (EGF), $5 \mathrm{mg} / \mathrm{mL}$ insulin-transferrin-selenium (Gibco), $0.1 \mathrm{mM}$ 2-phospho-L-ascorbic acid trisodium salt (Sigma-Aldrich, St. Louis, MO, USA), $10^{-8} \mathrm{M}$ dexamethasone, and $50 \mu \mathrm{g} / \mathrm{mL}$ gentamicin (Life Technologies, Grand Island, NY, USA). After reaching $90 \%$ confluence, cells were differentiated to keratocytes [52] by culturing in advanced DMEM with $10 \mathrm{ng} / \mathrm{mL}$ fibroblast growth factor-2 (Sigma-Aldrich), $0.1 \mathrm{ng} / \mathrm{mL}$ transforming growth factor- $\beta 3,50 \mu \mathrm{g} / \mathrm{mL}$ gentamicin, and $1 \%$ antibiotic-antimycotic (Gibco). Following 2 weeks of incubation, cells were seeded at a concentration 
of $1 \times 10^{5}$ cells $/ \mathrm{cm}^{2}$ and maintained in low serum media (Advanced DMEM (Gibco), 1\% v/v FBS, $300 \mu \mathrm{g} / \mathrm{mL}$ ampicillin) until seeded with SELP nanoparticles at approximately 4 weeks. SELP and ANS-loaded SELP nanoparticles were prepared as described then diluted in culture medium to a final concentration of $0.1-1 \mathrm{mg} / \mathrm{mL}$ and seeded onto cells for a $24 \mathrm{~h}$ incubation period. The media was aspirated, and the cells washed with PBS prior to paraformaldehyde (PFA) fixation.

\subsection{Immunohistochemistry}

Cultures were fixed with $4 \%$ w/v PFA (Santa Cruz Biotechnology, Dallas, TX, USA) in PBS for $15 \mathrm{~min}$ at $25^{\circ} \mathrm{C}$ for immunohistochemistry. After fixation, samples were washed three times with PBS and permeabilized with $0.1 \% \mathrm{v} / \mathrm{v}$ Triton-X-100 (Sigma, St. Louis, MO, USA) at $25^{\circ} \mathrm{C}$ for $15 \mathrm{~min}$ followed by 3 PBS washes. Next, cells were incubated with a $3 \% \mathrm{w} / \mathrm{v}$ bovine serum albumin (BSA) blocking solution (ThermoFisher) for $1 \mathrm{~h}$ at $25^{\circ} \mathrm{C}$ with agitation. After removing the BSA solution, cells were incubated with primary antibody solutions containing Alexa FluorTM 647 phalloidin (1:40, ThermoFisher, A22287) and anti-human Mucin2 (Mouse, 1:50, Abcam, ab11197) in PBS for $16 \mathrm{~h}$ at $4{ }^{\circ} \mathrm{C}$ with agitation. Primary antibodies were removed, and cultures were washed three times with PBS before addition of anti-Mouse IgG secondary antibody, Alexa FluorTM 488 conjugate (Donkey, 1:100, ThermoFisher, A21202), which was incubated with agitation for $1 \mathrm{~h}$ at $25^{\circ} \mathrm{C}$. All cultures were washed three times with PBS with agitation for 5 min at $25^{\circ} \mathrm{C}$ prior to fluorescence microscopy. Control samples were also incubated with 4',6-diamidino-2-phenylindole, dihydrochloride (DAPI) (ThermoFisher) at $1 \mu \mathrm{g} / \mathrm{mL}$ in PBS for $5 \mathrm{~min}$ at $25^{\circ} \mathrm{C}$ and washed three times immediately before fluorescence microscopy.

\subsection{Fluorescence Microscopy}

All samples were imaged using the Keyence BZ-X700 fluorescent microscope (Keyence, Elmwood Park, NJ, USA). Images were collected using either a 10X or 20X objective. Filters used include DAPI, GFP, and Texas Red with excitation/emission wavelengths of $360 \mathrm{~nm} / 420 \mathrm{~nm}, 470 \mathrm{~nm} / 525 \mathrm{~nm}$, and $560 \mathrm{~nm} / 645 \mathrm{~nm}$, respectively.

\subsection{Preparation of Biosimilar Mucus and Adhesion of ANS-Loaded SELP Nanoparticles}

Biosimilar mucus was prepared according to a published protocol [41]. All reagents were purchased from Sigma-Aldrich. Polysorbate $80(0.163 \% \mathrm{w} / \mathrm{v})$, phosphatidylcholine $(0.18 \% \mathrm{w} / \mathrm{v})$, and cholesterol $(0.36 \% \mathrm{w} / \mathrm{v})$ were dissolved in a solution of $137 \mathrm{mM} \mathrm{NaCl}, 10 \mathrm{mM}$ 2-( $\mathrm{N}$-morpholino)ethanesulfonic acid (MES), $1.3 \mathrm{mM} \mathrm{CaCl}_{2}$, and $1.0 \mathrm{mM} \mathrm{MgSO}_{4}, \mathrm{pH}$ 6.5. A second solution of BSA (3.1\% w/v), mucin from porcine stomach $(5 \% \mathrm{w} / \mathrm{v})$, and polyacrylic acid $(0.9 \% \mathrm{w} / \mathrm{v})$ was prepared in the same buffer excluding $\mathrm{NaCl}$. The solutions were mixed in a 1:9 ratio to obtain the necessary final volume. The $\mathrm{pH}$ was adjusted to 6.5, aliquoted in a 48-well plate in $500 \mu \mathrm{L}$ aliquots and equilibrated at $4{ }^{\circ} \mathrm{C}$ for $16 \mathrm{~h}$ to form a thin layer on the bottom of the well plate. Following the equilibration step, the SELP nanoparticle samples were seeded on the biosimilar mucus at $0.1 \mathrm{mg} / \mathrm{mL}$ and incubated at $37^{\circ} \mathrm{C}$ for $24 \mathrm{~h}$. Samples were then washed three times with PBS before fluorescence imaging. For washing, PBS was added to each well followed by agitation at $25{ }^{\circ} \mathrm{C}$ for $5 \mathrm{~min}$. The plate was then centrifuged at $5000 \mathrm{rpm}$ for $5 \mathrm{~min}$ and the supernatant carefully removed. This was repeated for a total of three washes.

\subsection{Cytotoxicity of SELP Nanoparticles and Biosimilar Mucus in Cell Culture Assays}

Toxicity of the SELP nanoparticles and the biosimilar mucus was assessed using a Vybrant ${ }^{\circledR}$ MTT Cell Proliferation Assay Kit (V-13154) (ThermoFisher) following the manufactures protocol. Briefly, Caco-2 and HT29-MTX cells were cultured in 24-well plates and incubated with either ANS-loaded nanoparticles $(0.1 \mathrm{mg} / \mathrm{mL})$ or biosimilar mucus for $24 \mathrm{~h}$. Following incubation, the cell media was removed and replaced with phenol red-free media. A $12 \mathrm{mM}$ stock of MTT 3-(4,5-dimethylthiazol-2-yl)-2,5-diphenyltetrazolium bromide (MTT) was prepared by dissolving $5 \mathrm{mg}$ of MTT in $1 \mathrm{~mL}$ of sterile PBS. Ten microliter of the MTT stock solution was added to each well containing $100 \mu \mathrm{L}$ of phenol-free media and incubated for $4 \mathrm{~h}$ at $37^{\circ} \mathrm{C}$. MTT was then solubilized 
by adding $50 \mu \mathrm{L}$ of dimethyl sulfoxide (DMSO) with incubation at $37^{\circ} \mathrm{C}$ for $10 \mathrm{~min}$ after which the absorbance of the samples was measured at $540 \mathrm{~nm}$. An average of three absorbance measurements is reported.

\subsection{Statistical Analysis}

Statistical significance was determined based on a one-way or two-way analysis of variance (ANOVA), where appropriate, with alpha set to 0.05 (GraphPad Prism 7 for Windows, GraphPad Software, Version 7.03, La Jolla, CA, USA).

\section{Conclusions}

Transmucosal drug delivery systems are an important route for administration of a variety of drug classes. Development of mucoadhesive platforms that increase drug retention and absorption will greatly enhance the efficacy of transmucosal materials. The design flexibility afforded by genetic engineering technology allows for the formation of multifunctional, dynamic SELP nanoparticles. A major benefit of such systems is the ability to incorporate multiple functionalities into a single platform by implementing SELPs with unique physical and chemical properties into a composite material, unlike traditionally used materials that are often limited to a specific feature.

In the current report we detail the characteristics of model SELP-based mucoadhesive systems implementing four different protein sequences to fabricate micelle-like nanoparticles encapsulating ANS as a model compound and reporter. Through tailoring of the SELP primary sequence, we can generate chemically diverse SELP nanoparticle of precise size with high homogeneity. The utility of the SELP-based systems for mucoadhesion was explored by studying the affinity of the nanoparticles to an artificial mucus model, as well as by investigating the interactions of these systems in a mucosal cell model in vitro. The results indicated that the SELP-based approach provided a useful strategy to develop and study nanoparticles for transmucosal drug delivery in future studies.

Additional benefits of SELP-based designs include the ability to fabricate a variety of material formats, such as films, gels, and nanoparticles. Tailoring the sequence composition, structural properties, and stimuli-responsive features lend to the future development of SELPs to the design of novel drug delivery materials with controlled chemical and physical properties. However, additional studies are required to further probe drug release and efficacy using these systems. Future studies will investigate the use of engineered SELPs for fabrication of mucoadhesive materials.

Supplementary Materials: The following are available online at http://www.mdpi.com/2079-4983/10/4/49/s1, Figure S1: Fluorescence spectra of SELP proteins. Figure S2: Representative fluorescence microscopy images of Caco-2 and HT29-MTX untreated cells. Figure S3: Representative fluorescence microscopy images of hCSSCs.

Author Contributions: Conceptualization, R.N.P., Q.X., and D.L.K.; methodology, R.N.P. and T.B.M.; validation, R.N.P., W.A.W., and T.B.M.; formal analysis, R.N.P. and T.B.M.; investigation, R.N.P. and W.A.W.; resources, D.L.K.; data curation, R.N.P., W.A.W., and T.B.M.; writing-original draft preparation, R.N.P.; writing-review and editing, R.N.P., T.B.M., W.A.W., Q.X., and D.L.K.; visualization, R.N.P., W.A.W., T.B.M., Q.X., and D.L.K.; supervision, D.L.K.; project administration, D.L.K.; funding acquisition, D.L.K.

Funding: This research was funded by the NIH (P41EB002520, R01NS094218, U19AI131126) and the ARO (W911NF-17-1-0384).

Conflicts of Interest: The authors declare no conflict of interest.

\section{References}

1. Bansil, R.; Turner, B.S. Mucin structure, aggregation, physiological functions and biomedical applications. Curr. Opin. Colloid Interface Sci. 2006, 11, 164-170. [CrossRef]

2. Lai, S.K.; Wang, Y.Y.; Hanes, J. Mucus-penetrating nanoparticles for drug and gene delivery to mucosal tissues. Adv. Drug Deliv. Rev. 2009, 61, 158-171. [CrossRef] [PubMed]

3. Dawson, M.; Krauland, E.; Wirtz, D.; Hanes, J. Transport of Polymeric Nanoparticle Gene Carriers in Gastric Mucus. Biotechnol. Prog. 2004, 20, 851-857. [CrossRef] [PubMed] 
4. Cavalli, R.; Gasco, M.R.; Chetoni, P.; Burgalassi, S.; Saettone, M.F. Solid lipid nanoparticles (SLN) as ocular delivery system for tobramycin. Int. J. Pharm. 2002, 238, 241-245. [CrossRef]

5. Grassin-Delyle, S.; Buenestado, A.; Naline, E.; Faisy, C.; Blouquit-Laye, S.; Couderc, L.J.; Le Guen, M.; Fischler, M.; Devillier, P. Intranasal drug delivery: An efficient and non-invasive route for systemic administration: Focus on opioids. Pharmacol. Ther. 2012, 134, 366-379. [CrossRef] [PubMed]

6. Leal, J.; Smyth, H.D.C.; Ghosh, D. Physicochemical properties of mucus and their impact on transmucosal drug delivery. Int. J. Pharm. 2017, 532, 555-572. [CrossRef] [PubMed]

7. Boegh, M.; Nielsen, H.M. Mucus as a Barrier to Drug Delivery-Understanding and Mimicking the Barrier Properties. Basic Clin. Pharmacol. Toxicol. 2015, 116, 179-186. [CrossRef] [PubMed]

8. Cone, R.A. Barrier properties of mucus. Adv. Drug Deliv. Rev. 2009, 61, 75-85. [CrossRef] [PubMed]

9. Petrou, G.; Jansson, R.; Högqvist, M.; Erlandsson, J.; Wagberg, L.; Hedhammar, M.; Crouzier, T. Genetically Engineered Mucoadhesive Spider Silk. Biomacromolecules 2018, 19, 3268-3279. [CrossRef] [PubMed]

10. Asim, M.H.; Moghadam, A.; Ijaz, M.; Mahmood, A.; Götz, R.X.; Matuszczak, B.; Bernkop-Schnürch, A. S-protected thiolated cyclodextrins as mucoadhesive oligomers for drug delivery. J. Colloid Interface Sci. 2018, 531, 261-268. [CrossRef] [PubMed]

11. Andreani, T.; Miziara, L.; Lorenzón, E.N.; De Souza, A.L.R.; Kiill, C.P.; Fangueiro, J.F.; Garcia, M.L.; Gremião, P.D.; Silva, A.M.; Souto, E.B. Effect of mucoadhesive polymers on the in vitro performance of insulin-loaded silica nanoparticles: Interactions with mucin and biomembrane models. Eur. J. Pharm. Biopharm. 2015, 93, 118-126. [CrossRef] [PubMed]

12. Sheng, J.; Han, L.; Qin, J.; Ru, G.; Li, R.; Wu, L.; Cui, D.; Yang, P.; He, Y.; Wang, J. N-Trimethyl Chitosan Chloride-Coated PLGA Nanoparticles Overcoming Multiple Barriers to Oral Insulin Absorption. ACS Appl. Mater. Interfaces 2015, 7, 15430-15441. [CrossRef] [PubMed]

13. Lamprecht, A.; Schäfer, U.; Lehr, C. Size-dependent bioadhesion of micro- and nanoparticulate carriers to the inflamed colonic mucosa. Pharm. Res. 2001, 18, 788-793. [CrossRef] [PubMed]

14. Behrens, I.; Pena, A.I.V.; Alonso, M.J.; Kissel, T. Comparative uptake studies of bioadhesive and non-bioadhesive nanoparticles in human intestinal cell lines and rats: The effect of mucus on particle adsorption and transport. Pharm. Res. 2002, 19, 1185-1193. [CrossRef] [PubMed]

15. Date, A.A.; Halpert, G.; Babu, T.; Ortiz, J.; Kanvinde, P.; Dimitrion, P.; Narayan, J.; Zierden, H.; Betageri, K.; Musmanno, O.; et al. Mucus-penetrating budesonide nanosuspension enema for local treatment of inflammatory bowel disease. Biomaterials 2018, 185, 97-105. [CrossRef] [PubMed]

16. Carlson, T.L.; Yildiz, H.; Dar, Z.; Lock, J.Y.; Carrier, R.L. Lipids alter microbial transport through intestinal mucus. PLoS ONE 2018, 13, e0209151. [CrossRef] [PubMed]

17. Adebisi, A.O.; Conway, B.R.; Adebisi, D.A.O. Lectin-conjugated microspheres for eradication of Helicobacter pylori infection and interaction with mucus. Int. J. Pharm. 2014, 470, 28-40. [CrossRef] [PubMed]

18. Sheng, J.; He, H.; Han, L.; Qin, J.; Chen, S.; Ru, G.; Li, R.; Yang, P.; Wang, J.; Yang, V.C. Enhancing insulin oral absorption by using mucoadhesive nanoparticles loaded with LMWP-linked insulin conjugates. J. Control. Release 2016, 233, 181-190. [CrossRef] [PubMed]

19. Salimi, E.; Le-Vinh, B.; Zahir-Jouzdani, F.; Matuszczak, B.; Ghaee, A.; Bernkop-Schnürch, A. Self-emulsifying drug delivery systems changing their zeta potential via a flip-flop mechanism. Int. J. Pharm. 2018, 550, 200-206. [CrossRef] [PubMed]

20. Zhang, L.; Qin, H.; Li, J.; Qiu, J.-N.; Huang, J.-M.; Li, M.-C.; Guan, Y.-Q. Preparation and characterization of layer-by-layer hypoglycemic nanoparticles with $\mathrm{pH}$-sensitivity for oral insulin delivery. J. Mater. Chem. B 2018, 6, 7451-7461. [CrossRef]

21. Gavin, A.; Pham, J.T.; Wang, D.; Brownlow, B.; Elbayoumi, T.A. Layered nanoemulsions as mucoadhesive buccal systems for controlled delivery of oral cancer therapeutics. Int. J. Nanomed. 2015, 10, 1569-1584.

22. Hejjaji, E.M.; Smith, A.M.; Morris, G.A. Evaluation of the mucoadhesive properties of chitosan nanoparticles prepared using different chitosan to tripolyphosphate (CS:TPP) ratios. Int. J. Boil. Macromol. 2018, 120, 1610-1617. [CrossRef] [PubMed]

23. Sosnik, A.; Das Neves, J.; Sarmento, B. Mucoadhesive polymers in the design of nano-drug delivery systems for administration by non-parenteral routes: A review. Prog. Polym. Sci. 2014, 39, 2030-2075. [CrossRef]

24. Brannigan, R.P.; Khutoryanskiy, V.V. Synthesis and evaluation of mucoadhesive acryloyl-quaternized PDMAEMA nanogels for ocular drug delivery. Colloids Surf. B Biointerfaces 2017, 155, 538-543. [CrossRef] [PubMed] 
25. Mahdi, M.H.; Conway, B.R.; Smith, A.M. Development of mucoadhesive sprayable gellan gum fluid gels. Int. J. Pharm. 2015, 488, 12-19. [CrossRef] [PubMed]

26. Huang, W.; Tarakanova, A.; Dinjaski, N.; Wang, Q.; Xia, X.; Chen, Y.; Wong, J.Y.; Buehler, M.J.; Kaplan, D.L. Design of Multistimuli Responsive Hydrogels Using Integrated Modeling and Genetically Engineered Silk-Elastin-Like Proteins. Adv. Funct. Mater. 2016, 26, 4113-4123. [CrossRef] [PubMed]

27. Pereira, A.M.; Machado, R.; Da Costa, A.; Ribeiro, A.; Collins, T.; Gomes, A.C.; Leonor, I.B.; Kaplan, D.L.; Reis, R.L.; Casal, M. Silk-based biomaterials functionalized with fibronectin type II promotes cell adhesion. Acta Biomater. 2017, 47, 50-59. [CrossRef] [PubMed]

28. Roberts, E.G.; Rim, N.G.; Huang, W.; Tarakanova, A.; Yeo, J.; Buehler, M.J.; Kaplan, D.L.; Wong, J.Y. Fabrication and Characterization of Recombinant Silk-Elastin-Like-Protein (SELP) Fiber. Macromol. Biosci. 2018, 18, e1800265. [CrossRef] [PubMed]

29. Zhou, M.-L.; Qian, Z.-G.; Chen, L.; Kaplan, D.L.; Xia, X.-X. Rationally Designed Redox-Sensitive Protein Hydrogels with Tunable Mechanical Properties. Biomacromolecules 2016, 17, 3508-3515. [CrossRef] [PubMed]

30. Elzoghby, A.O.; Samy, W.M.; Elgindy, N.A. Protein-based nanocarriers as promising drug and gene delivery systems. J. Control. Release 2012, 161, 38-49. [CrossRef] [PubMed]

31. Xia, X.X.; Wang, M.; Lin, Y.; Xu, Q.; Kaplan, D.L. Hydrophobic drug-triggered self-assembly of nanoparticles from silk-elastin-like protein polymers for drug delivery. Biomacromolecules 2014, 15, 908-914. [CrossRef] [PubMed]

32. Megeed, Z.; Cappello, J.; Ghandehari, H. Genetically engineered silk-elastinlike protein polymers for controlled drug delivery. Adv. Drug Deliv. Rev. 2002, 54, 1075-1091. [CrossRef]

33. Price, R.; Poursaid, A.; Cappello, J.; Ghandehari, H. In vivo evaluation of matrix metalloproteinase responsive silk-elastinlike protein polymers for cancer gene therapy. J. Control. Release 2015, 213, 96-102. [CrossRef] [PubMed]

34. Xia, X.X.; Xu, Q.; Hu, X.; Qin, G.; Kaplan, D.L. Tunable self-assembly of genetically engineered silk-elastin-like protein polymers. Biomacromolecules 2011, 12, 3844-3850. [CrossRef] [PubMed]

35. Wang, Q.; Xia, X.; Huang, W.; Lin, Y.; Xu, Q.; Kaplan, D.L. High Throughput Screening of Dynamic Silk-Elastin-Like Protein Biomaterials. Adv. Funct. Mater. 2014, 24, 4303-4310. [CrossRef] [PubMed]

36. Martin-Moldes, Z.; Ebrahimi, D.; Plowright, R.; Dinjaski, N.; Perry, C.C.; Buehler, M.J.; Kaplan, D.L. Intracellular Pathways Involved in Bone Regeneration Triggered by Recombinant Silk-silica Chimeras. Adv. Funct. Mater. 2018, 28, 1702570. [CrossRef] [PubMed]

37. Dinjaski, N.; Plowright, R.; Zhou, S.; Belton, D.J.; Perry, C.C.; Kaplan, D.L. Osteoinductive recombinant silk fusion proteins for bone regeneration. Acta Biomater. 2017, 49, 127-139. [CrossRef] [PubMed]

38. Bushmarina, N.A.; Kuznetsova, I.M.; Biktashev, A.G.; Turoverov, K.K.; Uversky, V.N. Partially folded conformations in the folding pathway of bovine carbonic anhydrase II: A fluorescence spectroscopic analysis. ChemBioChem 2001, 2, 813-821. [CrossRef]

39. Kim, W.; Thévenot, J.; Ibarboure, E.; Lecommandoux, S.; Chaikof, E.L. Self-Assembly of Thermally Responsive Amphiphilic Diblock Copolypeptides into Spherical Micellar Nanoparticles. Angew. Chem. 2010, 122, 4353-4356. [CrossRef]

40. Fujita, Y.; Mie, M.; Kobatake, E. Construction of nanoscale protein particle using temperature-sensitive elastin-like peptide and polyaspartic acid chain. Biomaterials 2009, 30, 3450-3457. [CrossRef] [PubMed]

41. Birch, D.; Diedrichsen, R.G.; Christophersen, P.C.; Mu, H.; Nielsen, H.M. Evaluation of drug permeation under fed state conditions using mucus-covered Caco-2 cell epithelium. Eur. J. Pharm. Sci. 2018, 118, 144-153. [CrossRef] [PubMed]

42. Boegh, M.; Baldursdóttir, S.G.; Müllertz, A.; Nielsen, H.M. Property profiling of biosimilar mucus in a novel mucus-containing in vitro model for assessment of intestinal drug absorption. Eur. J. Pharm. Biopharm. 2014, 87, 227-235. [CrossRef] [PubMed]

43. Almeida, H.; Lobão, P.; Frigerio, C.; Fonseca, J.; Silva, R.; Quaresma, P.; Lobo, J.M.S.; Amaral, M.H. Development of mucoadhesive and thermosensitive eyedrops to improve the ophthalmic bioavailability of ibuprofen. J. Drug Deliv. Sci. Technol. 2016, 35, 69-80. [CrossRef]

44. Jain, A.; Hurkat, P.; Jain, A.; Jain, A.; Jain, A.; Jain, S.K. Thiolated Polymers: Pharmaceutical Tool in Nasal Drug Delivery of Proteins and Peptides. Int. J. Pept. Res. Ther. 2019, 25, 15-26. [CrossRef] 
45. Duan, H.; Lü, S.; Gao, C.; Bai, X.; Qin, H.; Wei, Y.; Wu, X.; Liu, M. Mucoadhesive microparticulates based on polysaccharide for target dual drug delivery of 5-aminosalicylic acid and curcumin to inflamed colon. Colloids Surf. B Biointerfaces 2016, 145, 510-519. [CrossRef] [PubMed]

46. Caramella, C.M.; Rossi, S.; Ferrari, F.; Bonferoni, M.C.; Sandri, G. Mucoadhesive and thermogelling systems for vaginal drug delivery. Adv. Drug Deliv. Rev. 2015, 92, 39-52. [CrossRef] [PubMed]

47. Mohammed, M.A.; Syeda, J.T.M.; Wasan, K.M.; Wasan, E.K. An Overview of Chitosan Nanoparticles and Its Application in Non-Parenteral Drug Delivery. Pharmaceutics 2017, 9, 53. [CrossRef] [PubMed]

48. Netsomboon, K.; Bernkop-Schnürch, A. Mucoadhesive vs. mucopenetrating particulate drug delivery. Eur. J. Pharm. Biopharm. 2016, 98, 76-89. [CrossRef] [PubMed]

49. Pridgen, E.M.; Alexis, F.; Farokhzad, O.C. Polymeric nanoparticle drug delivery technologies for oral delivery applications. Expert Opin. Drug Deliv. 2015, 12, 1459-1473. [CrossRef] [PubMed]

50. Allen, A.; Hutton, D.A.; Pearson, J.P. The MUC2 gene product: A human intestinal mucin. Int. J. Biochem. Cell Boil. 1998, 30, 797-801. [CrossRef]

51. Basu, S.; Hertsenberg, A.J.; Funderburgh, M.L.; Burrow, M.K.; Mann, M.M.; Du, Y.; Lathrop, K.L.; Syed-Picard, F.N.; Adams, S.M.; Birk, D.E.; et al. Human limbal biopsy-derived stromal stem cells prevent corneal scarring. Sci. Transl. Med. 2014, 6, 266ra172. [CrossRef] [PubMed]

52. Wu, J.; Du, Y.; Mann, M.M.; Funderburgh, J.L.; Wagner, W.R. Corneal stromal stem cells versus corneal fibroblasts in generating structurally appropriate corneal stromal tissue. Exp. Eye Res. 2014, 120, 71-81. [CrossRef] [PubMed]

(C) 2019 by the authors. Licensee MDPI, Basel, Switzerland. This article is an open access article distributed under the terms and conditions of the Creative Commons Attribution (CC BY) license (http://creativecommons.org/licenses/by/4.0/). 